\title{
CONTABILIDADE E ADMINISTRAÇÃO: FERRAMENTAS QUE AUXILIAM NA MANUTENÇÃO DAS MICRO E PEQUENAS EMPRESAS NO MERCADO
}

\author{
Kaio Caldeira dos Anjos, Matheus Henrique Vinha da Silva, Thais Rubia Ferreira Lepre \\ Universidade do Oeste Paulista - UNOESTE, Curso Ciências Contábeis, Presidente Prudente, SP. E-mail: \\ thaisrubia@unoeste.br
}

\begin{abstract}
RESUMO
Neste novo século a sociedade brasileira vem vivenciando transformações nunca vistas anteriormente, do ponto de vista empresarial, é possível notar o crescimento significativo de empresas disputando mercado, entre elas, as de micro e pequeno porte tem predominado. Apesar disso é inevitável constatar que na mesma rapidez que abrem muitas encerram suas atividades por dificuldades na gestão do negócio. Diante disso, se faz necessário trazer ferramentas contábeis e administrativas que auxiliem este tipo de negócio a reduzir os motivos que as levam ao fechamento, e esta é a justificativa para existência desta pesquisa. Que objetiva identificar ferramentas contábeis e administrativas podem ser aplicadas as micro e pequenas empresas com a finalidade de auxiliar na gestão e redução dos motivos que as levam ao encerramento de suas atividades. Quanto à metodologia, a investigação contou com abordagem qualitativa, tendo a pesquisa bibliográfica como instrumento de coleta de dados, e análise de conteúdo. Foi possível concluir que o diagrama de causa e efeito, o fluxograma, a DRE e o balanço patrimonial estão entre as ferramentas que podem auxiliar na redução dos motivos que levam as MPE's ao encerramento de suas atividades.
\end{abstract}

Palavras-chaves: Micro e Pequenas Empresas. Ferramentas. Contabilidade. Administração. Sobrevivência.

\section{ACCOUNTING AND ADMINISTRATION: TOOLS ASSISTING THE MAINTENANCE OF MICRO AND SMALL ENTERPRISES IN THE MARKET}

\begin{abstract}
In this new century Brazilian society has experienced changes never seen before, from a business point of view, it is possible to note the significant growth of companies vying for market, among them, the micro and small has predominated. Nevertheless it is inevitable to note that at the same speed that open many end their activities by difficulties in running the business. Therefore, it is necessary to bring accounting and administrative tools to assist this type of business to reduce the reasons that lead to the closure, and this is the reason for the existence of this research. Which aims to identify accounting and administrative tools can be applied micro and small businesses in order to help manage and reduce the motives that lead them to cease their activities. As for the methodology, the research included qualitative approach and the literature as a data collection instrument, and content analysis. It was concluded that the cause and effect diagram, flowchart, the DRE and the balance sheet are among the tools that can help reduce the reasons that the MSEs to cease their activities.
\end{abstract}

Keywords: Micro and Small Enterprises. Tools. Accounting. Management. Survival. 


\section{INTRODUÇÃO}

A abertura do mercado na década de 90 trouxe modificações no cenário empresarial brasileiro. De acordo com Dornelas (2008) nesta época houve um grande número de desempregados, devido ao fato do empresariado sentir a necessidade de cortar custos para competir com as empresas estrangeiras e ter visto na demissão a principal forma de concretizar esta economia.

Com isso muitos ex-funcionários buscando sustento e com dificuldades em conseguir novas colocações decidiram abrir negócios próprios. Ocasionando uma elevação no "[...] número de microempresas no Brasil, que entre 1996 e 2002, evoluiu de 2.956.749 para 4.605.607, com crescimento acumulado de 55,8\% [...]" (DORNELAS, 2008, p.02). Até este momento existiam empresas pequenas, porém, em menor número, não tinham tanta expressividade na economia do país, mas a partir da década de 90 esta situação começou a se modificar, a quantidade de micro e pequenas empresas (MPE's) passou a aumentar consideravelmente.

Aumento este, que fica evidente se compararmos a quantidade desses negócios nos anos 80 e no inicio dos anos 2000. Em 1985, a participação dos pequenos negócios no PIB (Produto Interno Bruto) era de apenas 21\%, já em 2001, este percentual passou para 23,2\% e em 2011 atingiu 27\% (SEBRAE, 2015).

Tornando as micro e pequenas empresas fundamentais para o desenvolvimento econômico do Brasil, tendo em vista que este crescimento tornou estes negócios responsáveis por " $44 \%$ dos empregos formais em serviços, e aproximadamente $70 \%$ dos empregos gerados no comércio. Cerca de $50 \%$ das remunerações do setor formal de comércio foram pagas, em 2011, por MPE". (SEBRAE, 2014, p.07). Ou seja, enquanto existe um número relativamente pequeno de grandes organizações, tem-se uma quantidade enorme de pequenos negócios, que representam, mais de $50 \%$ da economia do país.

No entanto, para caracterizar micro e pequena empresa é preciso observar alguns itens, existe atualmente diversas formas de classificar um negócio, neste estudo optou-se pelas duas mais relevantes, que são faturamento anual e quantidade de funcionários. Iniciando pelo primeiro, que de acordo com o Art. 3ㅇ da Lei Complementar 123 de 14 de dezembro de 2006:

[...] consideram-se microempresas ou empresas de pequeno porte a sociedade empresária, a sociedade simples, a empresa individual de responsabilidade limitada e o empresário a que se refere o art. 966 da Lei no 10.406, de 10 de janeiro de 2002 (Código Civil), devidamente registrado no registro de empresas mercantis ou no registro civil de pessoas jurídicas, conforme o caso, desde que: I - no caso da microempresa, aufira, em cada ano-calendário, receita bruta igual ou inferior a $R \$ 360.000,00$ (trezentos e sessenta mil); e II - No caso da empresa de pequeno porte, aufira, em cada ano-calendário, receita bruta superior a $\mathrm{R} \$$ 360.000,00 (trezentos e sessenta mil reais) e igual ou inferior a $R \$ 3.600 .000,00$ (três milhões e seiscentos mil reais).

Nesse trecho é possível notar que o valor da receita anual é um critério que consta inclusive na legislação para caracterizar e diferenciar as micro e pequenas empresas das demais, considerando que elas desfrutam de simplificação na cobrança de tributos. A outra forma de classificação, por número de funcionários, é realizada pelo Serviço Brasileiro de Apoio as Micro e Pequenas Empresas (SEBRAE) , conforme exposto na tabela a seguir: 
Tabela 01. Classificação dos estabelecimentos segundo porte

\begin{tabular}{|l|l|l|}
\hline Porte & Indústria & Comércio e Serviços \\
\hline Microempresa (ME) & Até 19 empregados & Até 9 empregados \\
\hline $\begin{array}{l}\text { Empresa de Pequeno Porte } \\
\text { (EPP) }\end{array}$ & De 20 a 99 empregados & De 10 a 49 empregados \\
\hline Empresa de médio porte & De 100 a 499 empregados & De 50 a 99 empregados \\
\hline Grandes empresas & 500 ou mais empregados & 100 ou mais empregados \\
\hline
\end{tabular}

Fonte: SEBRAE (2013).

Ou seja, para se enquadrar na modalidade de microempresa, considerando o segmento a empresa pode ter até 19 empregados, já para ser considerada de pequeno porte, esse número pode chegar a 99 funcionários se o negócio estiver no ramo de comércio ou serviços.

Estas duas classificações foram desenvolvidas considerando aspectos comuns nestas modalidades de negócio. $E$ além dessas características as micro e pequenas empresas apresentam outras, porém, entre elas tem-se destacado um aspecto negativo comumente encontrado: a dificuldade em manter o negócio ativo no mercado.

De acordo com um estudo realizado pelo SEBRAE (2013) em 2013, a taxa de mortalidade vem diminuindo com o passar do tempo, mas ainda é alta, se considerarmos que a cada 100 novos negócios 24 fecham as portas nos dois primeiros anos de atividade.

Situação esta que pode ser considerada ruim para o desenvolvimento econômico do país, pois a manutenção destes negócios no mercado gera emprego e renda, aumentando a necessidade de produção, movimento assim, o ciclo da economia.

A este fechamento são atribuídos vários motivos, existe uma diversidade de autores que apresenta visões diferentes e/ou complementares para esta situação. De acordo com Santos e Pereira (1995) entre os fatores que contribuem para o fracasso desses negócios, esta a ausência de experiência empresarial; a falta de competência para gerenciar; o excesso de imobilização do capital em ativos fixos; a ausência de controles de custos e de gestão financeira; a falta de informações gerenciais; entre outros. Disto é possível inferir que para os autores, a ausência de conhecimentos administrativos, principalmente financeiros é um dos determinantes do encerramento das atividades das micro e pequenas empresas, além de problemas contábeis, como a ausência de relatórios que permitam visualizar a situação do negócio para tomada de decisão acertada.

Segundo relatório intitulado 'Causas de desaparecimento das micro e pequenas empresas', disponibilizado pelo Instituo Brasileiro de Planejamento Tributário - IBPT (2013, p. 03):

As principais causas do desaparecimento das micro e pequenas empresas brasileiras são: - Falta de planejamento e informações do mercado = $41,64 \%$ - Complexidade tributária e burocracias $=16,51 \%$ - Dificuldade no acesso a crédito financeiro e a investimentos $=14,43 \%$ - Tecnologias de gestão complexas e de alto custo $=11,76 \%$ - Brigas familiares ou de sócios $=6,65 \%$ - Falência $=4,27 \%$ - Encerramento espontâneo de atividades (doença, morte, falta de estímulo à manutenção do negócio) $=2,51 \%$ Outras causas (desatualização tecnológica, política econômica, etc) = $2,23 \%$.

Estes dados vão de encontro ao que Santos e Pereira (1995) externaram, considerando que é possível perceber que questões relacionadas aos aspectos administrativos e contábeis do 
negócio se sobressaem e permeiam os motivos que levam as micro e pequenas empresas ao encerramento de suas atividades prematuramente. Isso porque ambas exercem papel fundamental em qualquer negócio.

A Contabilidade costuma ser chamada de linguagem da empresa. Trata-se de um sistema de coletar, sintetizar, interpretar e divulgar, em termos monetários, informações sobre uma organização. Como qualquer outro sistema de informação, a Contabilidade passa por contínua evolução na busca de aperfeiçoamento de seus métodos e processos. (PIZZOLATO, 2000, p. 01).

Ou seja, ela exerce a função de demonstrar de modo sistematizado as informações financeiras da organização para todos os públicos interessados. Como reforçam Corbari e Macedo (2012, p.16):

A finalidade da contabilidade é prestar informações aos seus usuários. Porém, usuários internos e externos possuem necessidades distintas de informações. Para atender aos diversos usuários, a contabilidade dividi-se em dois ramos: a contabilidade financeira e a contabilidade gerencial.

Sendo a contabilidade financeira preocupada em fornecer dados ao público externo (acionistas, fornecedores, bancos, governo, etc.), pois, "preocupa-se com os registros de fatos passados que afetaram o patrimônio, abrange a entidade como um todo e está condicionada às normas legais que regulamentam a matéria" (CORBARI; MACEDO, 2012, p.17) enquanto a contabilidade gerencial é imprescindível para tomada de decisão em todas as esferas do negócio, ao passo que "[...] é o ramo da Contabilidade que tem por objetivo fornecer instrumentos aos administradores de empresas que os auxiliem em suas funções gerenciais" (CREPALDI, 2008, p.05). Por isso é o ramo da contabilidade capaz de municiar os gestores das micro e pequenas empresas com as ferramentas necessárias para gestão e manutenção dos seus negócios no mercado.

Já a administração é responsável pelo direcionamento e pela tomada de decisão em todos os aspectos, tendo em vista que "administração nada mais é do que a condução racional das atividades de uma organização" (CHIAVENATO, 2004, p.02), assim, pode-se dizer que ela tem papel definidor na sobrevivência ou insolvência de qualquer negócio no mercado.

Portanto a junção da Contabilidade com a Administração, através de suas ferramentas é imprescindível para boa gestão e sobrevivência das micro e pequenas empresas,considerando que a primeira municia a segunda com os relatórios e informações indispensáveis para condução adequada do negócio, neste sentido,

as ferramentas de gestão são cada vez mais necessárias nas organizações, já que elas proporcionam um diferencial competitivo para as empresas, que por meio de seu uso podem conhecer afundo seu comportamento, munindo-se de informações precisas e antecipando-se aos acontecimentos futuros, tornando a tomada de decisão mais efetiva e destacando melhor os resultados alcançados. (FREITAS; MELO, 2013, p. 01).

Assim, se faz necessário expor ferramentas contábeis e administrativas uteis na redução dos motivos que levam ao encerramento das atividades as organizações de micro e pequeno porte, tendo em vista a representatividade que elas tem na economia brasileira, justificando a existência deste estudo, que beneficiará a todos os micro e pequenos empresários com a informação acerca destas ferramentas.

\section{FERRAMENTAS ADMINISTRATIVAS E CONTÁBEIS UTEIS NA GESTÃO DAS ORGANIZAÇÕES}

Dentre as ferramentas administrativas mais usuais para observar, analisar e buscar problemas organizações esta: o fluxograma, e o diagrama causa e efeito. 
Conforme Barners (1977) o fluxograma é a técnica para se registrar um processo de forma compacta. É utilizado com a finalidade de tornar possível sua compreensão e posterior melhoria, tendo como objetivo representar os diversos passos do processo produtivo. Os fluxogramas são muito úteis no estudo associado às etapas e a fazer rodar o ciclo de produção.

Assim, o fluxograma é ferramenta fundamental para análise detalhada dos métodos de processo e rotina de um departamento e/ou área da organização. Tendo como benefícios a possibilidade de correção/eliminação de anormalidades ou etapas, e permite visualização de etapas que necessitam de padronizações, relações interdepartamentais e relações entre etapas e fases.

O diagrama de causa e efeito ou diagrama de Ishikawa é "utilizado para apresentar a relação entre o resultado de um processo (efeito) e as suas diversas causas" (CHAMON, 2008, p.63), objetiva facilitar a identificação das causas de problemas que devem ser sanados.

Já as ferramentas contábeis, servem como fomentadoras de informações, sendo essas indispensáveis para qualquer empresa, independente do porte, é por meio da aplicabilidade das ferramentas contábeis gerenciais, que o processo de desenvolvimento de estratégias de trabalho torna-se mais fácil, no auxilio na tomada de decisões. Para Vieira $(2008$, p. 19) "as ferramentas gerenciais de contabilidade permitem uma visualização das necessidades e possibilidades das empresas, auxiliando o gestor na tomada de decisão e no estabelecimento das estratégias empresariais".

Dentre as ferramentas contábeis tem-se os relatórios, que tem por objetivo auxiliar os micro e pequenos empresários na gestão de seus negócios, produzindo informações úteis e confiáveis. ludícibus e Marion (2002, p. 73) conceituam relatórios contábeis como "a expressão resumida e ordenada de dados colhidos pela contabilidade. Ele objetiva relatas às pessoas que utilizam os dados os principais fatos registrados por aquele setor em determinado período". Dois relatórios fundamentais para essas tomadas de decisões são: o Balanço patrimonial e a Demonstração de Resultado do Exercício - DRE.

O Balanço Patrimonial traz de forma resumida informações pertinentes sobre os direitos e obrigações da entidade e sobre a riqueza dos sócios representada pelo patrimônio líquido. No que se refere a DRE, pode-se dizer que este relatório demonstra de forma organizada como a entidade renova seu ciclo e movimenta seus recursos produtivos com intuito de gerar riquezas a cada instante. Ribeiro (2002, p. 38) destaca a importância da DRE: "a partir dessa demonstração, podese verificar o resultado que a empresa obteve no desenvolvimento de suas atividades durante um determinado período, geralmente igual a um ano".

Diante deste cenário onde várias empresas de micro e pequeno porte tem suas atividades com um curto período de tempo, por falta de conhecimentos do empresário, este artigo tem como objetivo identificar ferramentas contábeis e administrativas que podem ser aplicadas as micro e pequenas empresas com a finalidade de auxiliar na gestão e redução dos motivos que as levam ao encerramento de suas atividades.

\section{METODOLOGIA}

Este artigo foi elaborado com base em uma abordagem qualitativa, que de acordo com Gonsalves (2005, p. 58) "[...] preocupa-se com a compreensão, com a interpretação do fenômeno, considerando o significado que os outros dão às suas práticas". Neste sentido, a pretensão é abordar subjetivamente os fatos, de modo interpretativo sem mensuração ou emprego de análises estatísticas.

Como instrumento de coleta de informações, foi utilizada a pesquisa bibliográfica que para Marconi e Lakatos (2010, p. 142) "[...] é um apanhado geral sobre os principais trabalhos já realizados, revestidos de importância, por serem capazes de fornecer dados atuais e relevantes 
relacionados com o tema". Ou seja, esta pesquisa foi viabilizada por meio de livros, leis e materiais já divulgados oferecendo uma nova visão a partir da junção do que foi encontrado.

E para analise dos dados coletados o instrumento selecionado foi a analise de conteúdo. Tendo em vista que "[...] através da análise de conteúdo, podemos caminhar na descoberta do que está por trás dos conteúdos manifestos, indo além das aparências do que está sendo comunicado" (GOMES, 2007, p. 84). Ou seja, esta analise possibilitará enxergar além do óbvio, indo além do que parece ser, para o que realmente é.

\section{CONCLUSÃO}

Este artigo teve como proposta identificar quais ferramentas administrativas e contábeis podem ser aplicadas as micro e pequenas empresas com a finalidade de auxiliar na gestão e redução dos motivos que as levam ao encerramento de suas atividades. Ao longo do estudo, com base nos dados coletados bibliograficamente foi possível concluir que as ferramentas administrativas e contábeis têm como objetivo coletar dados e auxiliar nas tomadas de decisões dentro de uma organização, podendo ajudar no momento das análises de problemas e no planejamento e gestão de projetos. Entre as mais usuais com relação a gestão e redução dos motivos que levam ao encerramento de atividades esta: diagrama de causa e efeito, fluxograma, DRE e balanço patrimonial.

\section{REFERÊNCIAS}

CHAMON, E. M. Q. O. Gestão integrada de organizações. Rio de Janeiro: Brasport, 2008.

CHIAVENATO, I. Introdução à teoria geral da administração. 7.ed. Rio de Janeiro: Editora Campus, 2004.

CORBARI, E. C.; MACEDO, J. J.Administração estratégica de custos. Curitiba: IESDE, 2012.

CREPALDI, S. A. Contabilidade gerencial: teoria e prática. 4. ed. São Paulo: Atlas, 2008.

DORNELAS, J. C. A. Empreendedorismo: transformando ideias em negócios. 3. ed. Rio de Janeiro: Elsevier, 2008.

FREITAS, C. M. F.; MELO, V. S. Principais ferramentas de gestão aplicadas na faculdade de ciências sociais aplicadas do sul de minas - facesm. Encontro Científico Sul Mineiro de Administração, Contabilidade e Economia. Itajubá: 2013. Disponível em: < http://www.facesm.br/userfiles/webfiles/Artigo\%2011.pdf>. Acesso em: 27 fev. 2016.

GIBBS, G. Analise de dados qualitativos. Porto Alegre: Artmed, 2009.

GOMES, R. Análise e interpretação de dados de pesquisa qualitativa. In: MINAYO, M. C. de S (Org.). Pesquisa social: teoria, método e criatividade. 26. ed. Petrópolis: Vozes, 2007. p. 79-107.

IBPT. Causas de desaparecimento das micros e pequenas empresas . 2013. Disponível em: $<$ http://www.ibpt.com.br/img/uploads/novelty/estudo/701/Causas

DeDesaparecimentoDasMicrosEPequenasEmpresas.pdf>. Acesso em: 01 mar. 2016.

IUDÍCIBUS, S.; MARION, J. C. A contabilidade e o contador. In: Introdução à teoria da contabilidade para nível de graduação. 3. ed. São Paulo: Atlas, 2002.

Lei Complementar 123 de 14 de Dezembro de 2006. Disponível em: <http://www.planalto.gov.br/ccivil 03/leis/lcp/lcp123.htm> Acesso em: 14 jan. 2016. 
MARCONI, M. A.; LAKATOS, E. M. Fundamentos de metodologia científica. 7. ed. São Paulo: Atlas, 2010.

PIZZOLATO, N. D. Introdução à Contabilidade Gerencial. 2.ed. são Paulo: Pearson Makron Books, 2000.

RIBEIRO, O. M. Contabilidade Gerencial Fácil. 4. ed. São Paulo: Saraiva, 2002.

SANTOS, S. A.; PEREIRA, H.r J. Criando seu próprio negócio: como desenvolver o potencial empreendedor. Brasília: Ed. SEBRAE, 1995.

SEBRAE. Micro e Pequenas Empresas geram 27\% do PIB do Brasil. Disponível em: <http://www.sebrae.com.br/sites/PortalSebrae/ufs/mt/noticias/Micro-e-pequenas-empresasgeram-27\%25-do-PIB-do-Brasil>. Acesso em 10 jul. 2016.

SEBRAE. Participação das Micro e Pequenas Empresas na Economia Brasileira. Brasilia: SEBRAE, 2014. Disponível em: http://www.sebrae.com.br/Sebrae/Portal\%20Sebrae/Estudos\%20e\%20Pe squisas/Participacao\%20das\%20micro\%20e\%20pequenas\%20empresas.pdf>. Acesso em: 10 jul. 2016.

SEBRAE. Sobrevivência das empresas no Brasil. Brasília, 2013. Disponível em: http://www.sebrae.com.br/Sebrae/Portal\%20Sebrae/Anexos/Sobrevivencia das empresas no B rasil=2013.pdf. Acesso em: 01 ago. 2016.

VIEIRA, E. T. V. 2008. As ferramentas contábeis e o empreendedorismo no desenvolvimento das micro e pequenas empresas: o caso das empresas de panificação da cidade de Campo Grande/MS. Disponível em: http://www.scholar.google.com.br. Acesso em: 13 ago. 2016. 